\title{
¿En qué ayuda el antibiograma al médico clínico en la atención de sus pacientes?
}

LUIS M. NORIEGA R.

\section{¿How does the in vitro susceptibility test help practitioners attending their patients?}

Palabras claves: Test de susceptibilidad in vitro; antimicrobianos; uso clínico.

Key words: In vitro susceptibility test; antibiotic; clinical usage

La resistencia antimicrobiana es un fenómeno en constante aumento en el ámbito nacional e internacional. Sin embargo, el desarrollo de nuevos antimicrobianos está en franco descenso, sin que existan expectativas de desarrollo de nuevas moléculas en un futuro cercano. A tal grado está llegando este problema que recientemente el congreso de E.U.A. aprobó la inversión de cuantiosas sumas de dinero para permitir el desarrollo de nuevas moléculas de antibacterianos y revertir esta lamentable asociación entre resistencia y ausencia de nuevos fármacos.

En este contexto, la comprensión y buena lectura del antibiograma cobra vital importancia, tanto por el interés del paciente como en una perspectiva de responsabilidad pública.

Al hablar de la utilidad del antibiograma para el médico clínico, el primer concepto a precisar es ¿qué es el antibiograma?

El antibiograma debe mirarse como la unión de múltiples conceptos que se integran en una sugerencia acerca de la actividad de un antimicrobiano sobre un determinado patógeno, presente en un determinado sitio anatómico.

Para una adecuada comprensión de éste, se debe dominar conocimientos, tanto sobre los mecanismos de resistencia bacteriana involucrados y del comportamiento biológico de algunos agentes antimicrobianos, como conocimientos de farmacocinética y farmacodinamia de los antibacterianos.

Incorporados los conceptos antes señalados, no sólo se debe leer el antibiograma, sino que debemos analizarlo, con lo que podemos llamar una lectura interpretativa. Luego de esta lectura, debemos actuar en consecuencia.

A continuación revisaremos, utilizando algunos casos clínicos simples, los distintos aspectos a analizar.

Caso Clínico 1: Paciente 48 años, portador de cardiopatía coronaria e infarto agudo de miocardio, que fuera sometido a una angiografia y colocación de dos stent en 1998, y estaba en tratamiento con ácido acetilsalicílico, propanolol y atorvastatina. Cursó recientemente con una sinusitis bacteriana que se trató con amoxicilina hasta hacía 10 días. Refería el antecedente de haber asistido a un gran asado familiar dos días antes de comenzar el cuadro actual.

Consultó en el servicio de emergencia por diarrea líquida, 7 a 8 deposiciones en el día, en moderada cantidad, sin pujo, tenesmo ni productos patológicos, desde hacía 24 horas. El grupo familiar y los amigos con los que comió estaban asintomáticos. Al examen físico estaba subfebril $\left(37,4^{\circ} \mathrm{C}\right)$, con hidratación límite, moderado compromiso del estado general y leve dolor abdominal, difuso, con ruidos hidroaéreos aumentados.

¿Qué análisis podemos hacer de este caso? ¿Corresponde la toma de cultivos y antibiograma?

El Comité de Microbiología de la SOCHINF, publicó el año 2002 un consenso sobre el estudio microbiológico del síndrome diarreico agudo, en 


\section{Tabla 1. Indicaciones para efectuar coprocultivo}

- Síndrome diarreico agudo en una de las siguientes condiciones:

- Diarrea severa que no cede a tratamiento sintomático

- Diarrea con sangre

- Diarrea prolongada en inmunodeprimidos

- Neonatos

- Antecedentes de viajes

- Estudio de brotes relacionados a agua o alimentos

- Estudios epidemiológicos

- Pacientes con enfermedades basales de riesgo

\# Adaptada de Síndrome diarreico agudo: Recomendaciones para el diagnóstico microbiológico. Comité de Microbiología SOCHINF. Rev Chil Infect 2002; 19(2): 101-13.

el que definen las indicaciones de cultivo y estudio de susceptibilidad in vitro en estos cuadros. Según este consenso, las indicaciones de solicitar cultivo y efectuar un estudio de susceptibilidad se limitan a las señaladas en las Tablas 1 y 2 .

La evolución del paciente fue positiva, con regresión del cuadro general y disminución de la diarrea en las siguientes 24 horas.

La conclusión en el análisis de este caso, es que no tenía indicación de toma de coprocultivo (salvo consideraciones de tipo epidemiológico) y en caso de realizarse el cultivo, no habría indicación de efectuar antibiograma para aplicación clínica, excepto por razones de vigilancia de la susceptibilidad de los enteropatógenos.

Caso Clínico 2: Paciente 15 años, con episodios de faringo-amigdalitis a repetición y uso de múltiples antimicrobianos, que consultó por episodio de fiebre y odinofagia con 3 días de evolución. El examen físico revelaba un aumento de volumen y presencia de placas de pus en ambas amígdalas, junto a adenopatías submaxilares bilaterales. Se le practicó un test para detección de antígenos de Streptococcus pyogenes en secreción faríngea, que resultó positivo y el cultivo fue igualmente positivo para $S$. pyogenes.

¿Cuál es el análisis y la conducta en este caso?

Lo primero, es considerar que en las infecciones respiratorias altas, el uso injustificado de antimicrobianos alcanza a 50 ó $60 \%$ de los casos, por lo que se recomienda siempre certificar la etiología bacteriana antes de indicar antibacterianos. Dada la sensibilidad y especificidad del test de detección de antígenos (85-90 y 95\% respectivamente), éste es suficiente en caso de ser positivo, por lo que se puede obviar el cultivo. En caso de contar con el cultivo, el antibiograma, no es necesario para evaluar susceptibilidad in
Tabla 2. Indicaciones para efectuar estudio de susceptibilidad in vitro

- Shigella

- Siempre (alta prevalencia de cepas MR y tratamiento eficaz)

\section{- Salmonella}

- Sólo cuando se plantea infección invasora

\# Adaptada de Síndrome diarreico agudo: Recomendaciones para el diagnóstico microbiológico. Comité de Microbiología SOCHINF. Rev Chil Infect 2002; 19(2): 10113.

vitro a penicilina ya que, hasta la fecha, $S$. pyogenes continúa siendo universalmente susceptible a penicilina. En caso de tener cultivo y ser necesario el uso de macrólidos por una alergia bien documentada a $\beta$-lactámicos, el antibiograma podría tener alguna justificación ya que se ha descrito en nuestro país hasta $\sim 10 \%$ de resistencia in vitro de $S$. pyogenes a macrólidos.

\section{Antibiograma y Streptococcus pneumoniae}

La resistencia de penicilina a Streptococcus pneumoniae, desde su aparición en España, a principio de los 80 , se ha convertido en una seria amenaza mundial. Su amplia diseminación no ha dejado a Chile fuera de este problema, siendo la cifra de resistencia en nuestro país de grado moderado, como se puede observar en la Tabla 3.

La aparición de este problema y la diversidad de territorios afectados por este microorganismo nos han obligado a darle especial atención.

Medición de concentración inhibitoria mínima. Habitualmente los puntos de corte para definir susceptibilidad y resistencia en un estudio de CIM no están estratificados según dónde esté localizada la infección y básicamente consideran las concentraciones séricas alcanzadas por los antibacterianos. Con el desarrollo de los nuevos conceptos farmacocinéticos y farmacodinamicos y la constatación de su importancia en el resultado del tratamiento de una infección, ha sido necesario incorporar estos conceptos frente a la elección de una terapia antimicrobiana adecuada.

La eficacia de los antibacterianos depende de diferentes parámetros según el tipo de antimicrobiano. Los $\beta$-lactámicos requieren de un tiempo prolongado sobre la CIM para ejercer un efecto adecuado, es decir son tiempo dependientes. Para su éxito se requieren concentraciones 4 veces sobre la CIM, mantenidas al menos por 
Tabla 3. Distribución de la resistencia de Streptococcus pneumoniae a penicilina según grupo etario

\begin{tabular}{|c|c|c|c|c|}
\hline \multirow[t]{2}{*}{ Grupo etario } & \multicolumn{3}{|c|}{ CIM Penicilina $(\mu \mathrm{g} / \mathrm{ml})$} & \multirow{2}{*}{$\begin{array}{l}\text { Total cepas } \\
\text { estudiadas }\end{array}$} \\
\hline & $\begin{array}{c}\mathbf{S} \\
<\mathbf{0 , 0 6}\end{array}$ & $\begin{array}{c}I \\
0,1-2,0\end{array}$ & $\begin{array}{c}\mathrm{R} \\
>\mathbf{2 , 0}\end{array}$ & \\
\hline$<5$ años & 72,8 & 14,3 & 12,8 & 530 \\
\hline$>5-<15$ años & 83,7 & 8,7 & 7,6 & 92 \\
\hline $15-60$ & 91,6 & 4,8 & 3,6 & 167 \\
\hline$>60$ años & 97,0 & 1,5 & 1,5 & 67 \\
\hline
\end{tabular}

Fuente: Laboratorio de Referencia, Instituto de Salud Pública de Chile.



Figura 1. Farmacodinamia: Farmacocinética versus CIM.

$40 \%$ del tiempo que transcurre entre dos dosis sucesivas (Figura 1).

En aminoglucósidos y quinolonas importa la relación entre el pico y la CIM. A más alta relación, mejor será el efecto antibacteriano logrado (Figura 1).

Conociendo la dosis y el intervalo de administración de un antimicrobiano $\beta$-lactámico, podemos suponer qué concentración será la máxima alcanzada durante el 40\% del tiempo interdosis. Esto se denomina el punto de corte PK/PD. Este punto puede no coincidir con la CIM medida in vitro para un agente en particular. A partir de estos conceptos surge la clara necesidad de contar puntos de corte por agente causal, territorio anatómico y para cada antibacteriano, y así asegurar una adecuada respuesta a la terapia antimicrobiana. Como señalamos, lo anterior es de extrema importancia para S. pneumoniae no siendo igual tratar una infección neumocóccica localizada en la sangre o en el pulmón, que si ella está en las meninges.

\section{Staphylococcus sp y antibiograma}

Caso Clínico 3: Paciente operado de recambio protésico de cadera izquierda doce meses antes. Ingresó por dolor en la cadera izquierda, enrojecimiento y secreción en la zona de la cicatriz quirúrgica. La tinción de Gram de dicha secreción mostró cocos grampositivos en racimos y el cultivo fue positivo para Staphylococcus epidermidis. Se informó el siguiente antibiograma: $\begin{array}{llll}\text { Penicilina } & \mathrm{R} & \text { Rifampicina } \mathrm{R}\end{array}$ Cloxacilina $\mathrm{R}$ Vancomicina $\mathrm{S}$ Cefazolina $\mathrm{S}$ Linezolid $\mathrm{S}$ Clindamicina $\quad \mathrm{R} \quad$ Gentamicina $\mathrm{S}$ Ciprofloxacina S Cotrimoxazol S

La pregunta en este caso es ¿con qué tratar? ¿Son todos los antimicrobianos, activos según este antibiograma, adecuados para tratar al paciente?

En la interpretación de antibiograma de Staphylococcus aureus y $S$. epidermidis, es posible incurrir en errores si no se siguen algunos principios básicos. Lo primero es contar con un laboratorio de microbiología confiable, ya que errores en la metodología utilizada pueden dar origen a resultados erróneos, los que a su vez condicionan tratamientos inadecuados.

En el antibiograma, lo primero es observar la susceptibilidad a oxacilina. De tratarse de una cepa resistente, sólo se debe confiar para la terapia en glicopéptidos, oxazolidinonas y en algunos casos, cotrimoxazol más rifampicina; no se debe usar cefalosporinas, macrólidos ni lincosamidas. Estos dos últimos grupos pueden ser activos in vitro pero, en las cepas oxacilina resistentes, el desarrollo de resistencia intra tratamiento es muy frecuente. Los aminoglucósidos sólo tienen utilidad limitada como fármaco sinérgico.

En todas las infecciones graves, la utilización de rifampicina como sinérgico es una muy buena alternativa, por lo que se debe contar siempre con la susceptibilidad a ella.

En aquellas situaciones como el caso clínico precedente, en el que haya un cuerpo extraño en la zona infectada, debemos considerar una posi- 
ble susceptibilidad in vitro heterogénea entre colonias de $S$. epidermidis, lo que puede llevarnos a engaño, asumiendo que todas las colonias y no sólo las predominantes son susceptibles a oxacilina. En estos casos es mejor asumir resistencia para el diseño de la terapia.

Algunos tipos de Staphylococcus coagulasa negativa, específicamente $S$. lugdinensis, pueden ser identificados como $S$. aureus, por lo que cuando se sospecha su presencia debe insistirse sobre la importancia de una buena identificación.

\section{Bacilos gramnegativos}

Por todos es conocido el creciente y evolutivo desarrollo de resistencia entre los bacilos gramnegativos. Esto se ve agravado por el escaso desarrollo de nuevas moléculas con actividad sobre ellos. En los últimos años, el único desarrollo en terapia antimicrobiana con nuevas familias de antibacterianos ha sido relacionado a especies grampositivas.

Caso Clínico 4: Paciente de 50 años cursando post operatorio de un cuadro de obstrucción intestinal, secundario a bridas (antecedentes de colecistectomía), con sufrimiento de asas que requirió resección. Presentó colecciones residuales que fueron drenadas, SDRA y falla renal que requirió apoyo dialítico. En terapia antibacteriana con ceftriaxona y metronidazol. Con posterioridad a una mejoría relativa y desconexión de ventilación mecánica, reapareció fiebre hasta $38,5^{\circ} \mathrm{C}$. Una TAC abdominal reveló la presencia de una colección que fue drenada por punción; el cultivo fue positivo para Escherichia coli, con el siguiente antibiograma:

$\begin{array}{llll}\text { Ampicilina } & \text { R } & \text { Imipenem } & \text { S } \\ \text { Ampicilina/sulbactam } & \text { R } & \text { Meropenem } & \text { S } \\ \text { Cefazolina } & \text { R } & \text { Cefepime } & \text { S } \\ \text { Cefuroxima } & \text { R } & \text { Cefoperazona/sulbactam } & \text { S } \\ \text { Ceftriaxona } & \text { R } & \text { Piperacilina/tazobactam } & \text { S } \\ \text { Ceftazidima } & \text { S } & \text { Ticarcilina/ác. clavulánico S } \\ \text { Ciprofloxacina } & \text { S } & \text { Gentamicina } & \text { R } \\ \text { Amikacina } & \text { S } & \text { Cotrimoxazol } & \text { R }\end{array}$

\section{¿Qué análisis podemos hacer de este antibio- grama?}

Lo primero es comprender que se trata una cepa intrahospitalaria, de un paciente sometido a terapia antibacteriana de amplio espectro y que en el antibiograma hay una discordancia en la susceptibilidad in vitro entre cefalosporinas de $3^{\circ}$ generación. Esa discordancia es muy sugerente de presencia de $\beta$-lactamasas de espectro extendido (BLEE).
La comprensión sobre la clasificación y rol de las $\beta$-lactamasas es cada vez más compleja y las BLEE han agregado un nuevo punto de complejidad, que ha obligado a los laboratorios de microbiología a modificar algunas conductas para lograr una buena detección de ellas. Las BLEE son $\beta$-lactamasas habituales con mutaciones menores.

Estas mutaciones, al ser puntuales, son dependientes del inóculo y requieren inóculos mayores para expresarse, pudiendo por esta razón dar falsos negativos (es decir, falsa susceptibilidad) in vitro. Estas enzimas son codificadas por genes localizados en plásmidos, lo que facilita su diseminación. Su presencia confiere resistencia a todos los $\beta$-lactámicos, salvo carbapenems y cefamecinas (cefoxitina y cefocetan). Estas enzimas se pueden ver en cualquier enterobacteria, siendo lo clásico en E. coli y Klebsiella spp. Varían en frecuencia de un centro a otro y en el mismo centro, de servicio clínico a servicio clínico. Es muy importante la vigilancia de su existencia y la interpretación de los antibiogramas debe ser cuidadosa. Aquellos casos con presencia de BLEE deben ser tratados con carbapenems, quinolonas y aminoglucósidos según los patrones de susceptibilidad in vitro. Las formas para medir la presencia de BLEE son variadas pero se basan en la formación de un diferente halo (inhibición de crecimiento) al comparar el antimicrobiano solo (menor halo) versus el antimicrobiano más un inhibidor, específicamente ácido clavulánico (mayor halo).

Caso Clínico 5: Paciente de 75 años, hipertenso, fumador y diabético, que ingresó a una UCI por una neumonía comunitaria y falla respiratoria, requiriendo ventilación mecánica. Los hemocultivos fueron positivo para Streptococcus pneumoniae susceptible a penicilina. A los 10 días de VM, estando en mejores condiciones, con control del cuadro séptico, pero aún con requerimiento de apoyo ventilatorio, presentó fiebre hasta $39^{\circ} \mathrm{C}$ y aumento de secreciones respiratorias. Un cultivo traqueal cuantitativo comprobó la presencia de Serratia $\mathrm{sp}>100.000$ colonias/ml, con el siguiente antibiograma:

Ampicilina: $\quad \mathrm{R}$ Ampicilina/sulbactam

Cefazolina

R Cefuroxima

Ceftriaxona

Ceftazidima

Amikacina

Ciprofloxacina

Meropenem

S Cefotaxima

S Gentamicina

Cefoperazona/sulbactam S

S Cotrimoxazol

$\mathrm{S}$ Imipenem

$S$ Cefepime

Piperacilina/tazobactam S Ticarcilina/ác. clavulánico S 
¿Qué análisis corresponde efectuar?

Se trata de infección intrahospitalaria, asociada a ventilación mecánica, causada por una cepa con resistencia natural inducible ( $\beta$-lactamasas tipo AMP C), caracterizada por su capacidad de des-reprimir genes de resistencia durante la terapia; en ella se debe prever la aparición de esta resistencia intratratamiento y no es recomendable usar cefalosporinas, haciendo excepción de cefepime. Este agente forma parte de un grupo de Enterobacteriaceas denominado SPICE, formado por Serratia sp, Proteus mirabilis, Citrobacter sp y Enterobacter sp. Todas tiene las mismas características, son habitualmente intrahospitalarias, poseen este gen $a m p C$ en su cromosoma y su expresión in vitro puede ser variable. Últimamente el panorama se ha vuelto más complejo al describirse este gen $\operatorname{ampC}$ en plásmidos que, por ser naturalmente transferibles, facilitan la diseminación de la resistencia mediada por este gen.

Caso Clínico 6: Paciente 65 años, sometido a laparotomía por abdomen agudo, documentándose una perforación de colon en relación a una neoplasia colónica. Se le realizó una resección intestinal, aseo quirúrgicos y quedó con laparotomía contenida. Evolucionó con fiebre persistente a pesar del drenaje quirúrgico y uso de ceftriaxona más ciprofloxacina y metronidazol.

Último cultivo: Pseudomona aeruginosa, con el siguiente antibiograma:

\begin{tabular}{|c|c|c|}
\hline ftriaxona & $\mathrm{S}$ & Ceftazidima \\
\hline Gentamicina & $\mathrm{R}$ & Amikacina \\
\hline Cotrimoxazol & $\mathrm{R}$ & Ciprofloxacina \\
\hline Imipenem & $\mathrm{S}$ & Meropenem \\
\hline Cefepime & $\mathrm{S}$ & Cefoperazona/sulbactam \\
\hline Piperacilina/tazobactam & $\kappa$ & Ticarcilina/ác. clavulánico \\
\hline
\end{tabular}

$\mathrm{Al}$ analizar este antibiograma, se debe considerar que no todas las cefalosporinas tienen actividad "antipseudomonas", independiente de lo que diga el antibiograma (sólo ceftazidima, cefoperazona y cefepime la tienen). Es importante considerar además que la discordancia de susceptibilidad in vitro a meropenem versus imipenem es real y está explicada por las PBPs sobre las que actúa cada uno de ellos. Meropenem se une a las PBP2 y 3, imipenem sólo a PBP2, lo que determina diferencias en actividad in vitro y clínica. Otro elemento es el hecho que $P$. aeruginosa es un microrganismo con potenciales múltiples mecanismos de resistencia por lo que se debe tratar siempre con dos antimicrobianos activos in vitro y asociados, para evitar emergencia de resistencia durante la terapia.

\section{¿Hacia donde vamos con el antibiograma?}

En la actualidad la biología molecular está dando pasos agigantados hacia responder en forma rápida y precisa sobre la detección de genes que codifiquen resistencia. Los problemas con esta tecnología son su costo, el que debiera aminorarse en la medida que se masifiquen estas técnicas y, en segundo lugar, el riesgo de detectar información genética de resistencia que no necesariamente se exprese.

Ya existen avances importantes en el estudio de resistencia a cloxacilina en Staphylococcus por detección de gen $m e c A$ y en investigación preclínica están la búsqueda de genes de resistencia en bacilos gramnegativos con alta prevalencia.

En un futuro que esperamos cercano, la biología molecular deberá estar integrada con las técnicas de microbiología convencional, en un intento de dar respuestas rápidas y precisas al problema emergente de la resistencia antimicrobiana.

Agradecimientos. A Patricia González A. por su valiosa colaboración en la preparación de este manuscrito.

\section{Bibliografía}

1.- García P. Resistencia bacteriana en Chile. Rev Chil Infect 2003; 20: S11-23.

2.- Morales R. Terapia de bacterias productoras de $\beta$ lactamasas de espectro extendido. Rev Chil Infect 2003; 20: S24-7.

3.- Jasovic A. Control de antimicrobianos, ¿Hasta donde duela? Rev Chil Infect 2003; 20: S63-9.

4.- Pérez C. Antibióticos en Unidad de Cuidados Intensivos: Uso empírico. Rev Chil Infect 2003; 20: S70-3.

5.- Capítulo II. Bacteriología, F: Antimicrobianos. Estudios de susceptibilidad antimicrobiana. En Abarca K, García P y Vial P, editores. Microbiología Clínica, Ediciones Universidad Católica de Chile. 2001, Santiago, Chile. P: 185-92.

6.- International Symposium on Antimicrobial Agents and Resistance, 2001-2003. www.isaar.org

7.- Craig W. Basic pharmacodynamics of antibacterial with clinical application to the use of $\beta$-lactams: Glycopeptides and Linezolid. Infect Dis Clin North Am 2003; 17: 479-501.

8.- Gill V J, Fedorko D P, Witebsky F G. The clinician and the Microbiology Laboratory. En Mandell, Douglas and Bennett's Principles and Practice of Infectious Diseases. Mandell GL, Bennett J E, Dolin R, editors. $5^{\circ}$ edition, 2000 pp: 184-222.

9.- Crespo M. del P. La lectura interpretativa del antibiograma: Una herramienta para predecir la resistencia bacteriana en el laboratorio de microbiología de rutina. http://colombiamedica.univalle.edu.co/Vol33 $\mathrm{N}^{\circ} 4 /$ cmn4a6.htm

Correspondencia a:

Luis Miguel Noriega Ricalde

lnoriega@alemana.cl 